\title{
PODSTICANJE ASERTIVNE KOMUNIKACIJE UČENIKA PUTEM RADIONIČARSKOG RADA U OKVIRU ODELJENSKE ZAJEDNICE
}

\author{
Danijela Milošević ${ }^{1}$ \\ Univerzitet u Nišu, Filozofski fakultet, Departman za pedagogiju (student DAS)
}

\begin{abstract}
Apstrakt: U radu je posvećena pažnja razmatranju asertivnog stila komunikacije koji se shvata kao konstruktivan obrazac koji doprinosi intenziviranju socijalnih interakcija učenika i formiranju kvalitetne pedagoške klime u odeljenju. U tom pogledu čas odeljenske zajednice se izdvaja i percipira kao potencijal za kreiranje i razvijanje nenasilne komunikacije i demokratskih odnosa učenika, a nastavnik kao ključni delatnik podsticanja saradničke atmosfere i prosocijalnog ponašanja učenika. Najveći doprinos u regulisanju interpersonalnih odnosa učenika sa jedne strane, i razvijanje kooperativnog i aktivnog učenja sa druge strane, vidi se u primeni radioničarskog rada. Stoga, praktična vrednost ovog rada je u predstavljanju pedagoške radionice koja je specijalno dizajnirana za potrebe osposobljavanja učenika za primenu asertivnog stila komunikacije. Ne treba izgubiti iz vida da uspostavljanje i razvoj uspešne interpersonalne komunikacije u nastavi velikim delom zavisi od nastavnika, pa je u fokusu ovog rada i razvoj njegovih socijalnih kompetencija. Shodno tome, usmerenost ka permanentnom obrazovanju i kontinuiranom razvoju refleksivne prakse je preoritet savremenog nastavnika, koji pretenduje da menja i inovira nastavi proces.
\end{abstract}

Ključne reči: interpersonalni odnosi, nenasilna komunikacija, pedagoška klima, radioničarski rad, stilovi komunikacije.

\section{Uvod}

U školskom kontekstu, komunikacija predstavlja kompleksan proces koji podrazumeva međuzavisnost ponašanja učesnika vaspitno-obrazovnog procesa. Karakteriše je aktivno uključivanje svih učesnika u ispunjavanju predviđenih ciljeva i zadataka vaspitno-obrazovne delatnosti (Jovanović, 2009), a njena svojstvenost se ogleda u komunikativnim, interaktivnim i perceptivnim komponentama (Zhamilya et al., 2013).

\footnotetext{
$\overline{1}$ d.milosevic-15811@filfak.ni.ac.rs

Stipendista Ministarstva prosvete, nauke i tehnološkog razvoja Republike Srbije.
} 
Da bi pedagoška komunikacija nosila obeležje efikasnosti neophodno je u njenoj suštini negovati uzajamno poštovanje i iskren i ravnopravni odnos među učesnicima. Jovanović (Jovanović, 2009) ukazuje na odlike efikasne pedagoške komunikacije: jasnost, dvosmernost, usklađenost sa psihofizičkim uzrastom sagovornika, usmerenost na podsticanje mišljenja, razvijenost govora, mogućnost izbora i razmene ideja. Takva komunikacija je demokratski orijentisana i kod učenika utiče na formiranje najpoželjnijeg - asertivnog stila komunikacije, koji utiče na stvaranje pozitivne slike o sebi i drugima i doprinosi celokupnom samorazvoju učenika.

Razvijati asertivnu komunikaciju na časovima odeljenske zajednice od izuzetnog je značaja za formiranje pozitivnih interpersonalnih odnosa i kvalitetne pedagoške klime. Ipak, nesumljivo se postavljaju mnogobrojna pitanja poput: kako stvoriti povoljne uslove za pospešivanje asertivnog stila komunikacije u školskom okruženju?, koje metode iskoristiti kao najadekvatnije u razvoju asertivne komunikacije?, kako motivsati nastavnike da razvijaju asertivnu komunikaciju među učenicima? Ova i mnoga druga pitanja itekako otvaraju prostor za proučavanje i razmatranje problematike asertivne komunikacije u nastavnoj praksi. Shodno tome, asertivna komunikacije će se nadalje tretirati kao poželjni stil komunikacije koji vodi ka pozitivnim efektima u interpersonalnim odnosima među učenicima, pri čemu se ukazuje i na značajnu ulogu nastavnika kao regulatora socijalnih odnosa u odeljenju. Predstavljena pedagoška radionica se nudi kao primer i pomoćni alat nastavnicima u osnaživanju asertivnog stila komunikacije u okviru odeljenske zajednice, a sve u svrhu unapređenja kvaliteta međusobnih odnosa učenika i socioemocionalne klime u odeljenju.

\section{Asertivni stil komunikacije učenika u vaspitno-obrazovnom procesu}

U savremenoj nastavnoj praksi komunikacija je od suštinskog značaja. Stil komunikacije je važna komponenta u rukovođenju nastavnim procesom i neophodan činilac u ostvarivanju saradnje svih učesnika vaspitno-obrazovnog rada. Način komunikacije oslikava obrazac ponašanja na osnovu koga nastavnici i učenici razvijaju međusobne odnose, pa se može reći da od stila komunikacije može zavisiti kvalitet interakcijskih relacija i pedagoška klima u odeljenju.

Kako asertivni stil komunikacije, prema dostupnim izvorima, predstavlja najpoželjniji obrazac ponašanja i najuspešniji način uspostavljanja međusobnih odnosa, tako on za obrazovni sistem ima naročit značaj. Primena asertivnog ponašanja može biti konstruktivna veština $u$ regulaciji socijalnih odnosa $u$ razredu. Učenici koji primenjuju asertivni stil komuniciranja pokazuju sposobnost da na jasan, direktan i iskren način izraze sopstveno mišljenje, stavove i osećanja, a u isto vreme poštuju osećanja, potrebe i prava drugih (Lambertz \& Blight, 2016). Ovakav obrazac ponašanja ukazuje na akciju koja isključuje uskraćivanje prava drugima, a istovremeno uključuje borbu i odbranu sopstvenih uz izražavanje pozitivnih 
osećanja (Alberti \& Emons, 1970). Primena asertivnog stila doprinosi razvijanju i sposobnosti empatije (Uzuntarla et al., 2016) i sopstvene svesti o odgovornom ponašanju (Ames, 2009). Od nivoa razvijenosti asertivnog stila zavisi i emocionalna i socijalna prilagođenost učenika (Moon, 2009). Asertivni učenici imaju razvijene socijalne kompetencije, veštine rešavanja problema i teže ka introspekciji (Güven, 2010). Kod njih je primetno veće samopouzdanje i samopoštovanje (Sarkova et al., 2013), a rezultati pokazuju i da se sa nivoom asertivnosti povećava motivacija učenika za akademska postignuća (Galata, 2018).

Međutim, da bi se osigurala efikasna komunikacija i formirali kvalitetni odnosi među učesnicima u školskoj zajednici veliku ulogu ima nastavnik. Tačnije, njegov stil komuniciranja određuje način njegovog rada i ponašanja u nastavnim situacijama (Havelka, 2000). On je kreator pozitivne psihosocijalne klime i model ponašanja koji može uticati na formiranje obrasca komunikacije i motivacije učenika za učenje (Eupena, 2012). Na primeru nastavnika učenici usvajaju veštine komunikacije i uče kako da sarađuju sa drugima (Havelka, 2000), pa je njegova uloga u nastavnom procesu od vitalnog značaja.

Nastavnik ima posebnu ulogu u razvoju interpersonalnih odnosa u okviru odeljenske zajednice. Putem časova odeljenske zajednice nastavnik može da formira poverenje i ostvari vaspitne i obrazovne ciljeve (Husić, 2009). Osim što nastavnicima čas odeljenske zajednice pruža više vremena da razvijaju odnose sa učenicima i među učenicima, omogućava im i upoznavanje mogućnosti učenika i prepoznavanje njihovih potreba (Koludrović, Jukić i Reić Ergovac, 2009). Na odeljenskoj zajednici se može ostvariti saradnička atmosfera koja predstavlja preduslov za formiranje nenasilne komunikacije i demokratskih odnosa (Ivanek i sar., 2011), pri čemu se nastavniku pruža prilika i da preventivno deluje u rešavanju potencijalnih problema među učenicima.

Međutim, da bi nastavnik razvio asertivno ponašanje učenika, neophodno je da kod njih kontinuirano razvija veštine asertivne komunikacije koje podrazumevaju: uspostavljanje i održavanje razgovora sa drugima, efikasno suočavanje sa konfliktnim situacijama, adekvatno izražavanje pozitivnih i negativnih emocija i veštine aktivnog slušanja (Romek, 2003). S tim u vezi, reklo bi se da je i te kako prepoznata potreba za kontinuiranim usavršavanjem nastavnika u domenu razvijanja pedagoškog pristupa i veština učenika za nenasilnu komunikaciju. Takav vid usavršavanja vodi ka kvalitetnim interpersonalnim odnosima koji doprinose ostvarivanju vaspitnih i obrazovnih ciljeva i kreiranju povoljne psihosocijalne klime, koja rezultira većom kohezijom učenika u školskoj zajednici.

\section{Efikasnost radioničarskog oblika rada u razvijanju asertivne komunikacije}

Radioničarski pristup je specifičan metod koji omogućava sticanje kompetencija kroz iskustveno, kooperativno i aktivno učenje (Ørngreen \& Levinsen, 2017). Kao metod osigurava ravnopravnost i povoljnu klimu učesnika i moderatora i 
daje mogućnost kombinovanja različitih metoda i tehnika (Johnson \& Onwuegbuzie, 2004). Radionice podstiču timski duh, kritičko mišljenje i pozitivnu interpersonalnu komunikaciju (Felder \& Brent, 2017). Brojna su istraživanja čiji su rezultati ukazali na efikasnost radioničarskog pristupa. Na primer, 2017. godine autor Manta (Manta, 2017) kroz svoje istraživanje je ukazao da su se interaktivne radonice pokazale visoko efikasnim u poboljšanju komunikacije nastavnika i učenika u nastavnom procesu, dok su drugi autori poput Likandera i saradnika (Lucander et al., 2012), kao i Nestela i Bejtsona (Nestel \& Betson, 1999), tome dodali i komunikativne veštine studenata. Na sličan način o radioničarskom pristupu govore i Kember i saradnici (Kember et al., 2008) ukazujći na njegov pozitivan uticaj na kvalitet učenja i disciplinu učenika, ali i savladavanje matematičkih operacija. Takođe, Salmon (Salmon, 2009) navodi da su učenici. pokazali veću motivisanost, participativnost i interakciju, što je zbog efikasnosti ove metode otvorilo potrebu obrazovanja nastavnika za njenu primenu u formalnom obrazovanju.

Radioničarska metoda pokazala se efikasnom u podsticanju asertivne komunnikacije. Naime, rezultati istraživanja ukazuju da se socijalne kompetencije učenika u nastavi mogu poboljšati putem primene asertivnog programa u školskom kontekstu (Obey-Jordan, 2007). Jedno takvo istraživanje sprovedeno je u istočnoj Turskoj 2011. godine sa studentima medicine. Ovo istraživanje pokazalo je da je trening asertivnosti baziran na radioničarskoj metodi doprineo u povećanju komunikacijskih veština studenata (Gultekin et al., 2018). Slično istraživanje o kome su pisali Hojat i saradnici (Hojjat et al., 2016) ukazalo je na značajne razlike između kontrolne i eksperimentalne grupe kod asolescenata. U toj populaciji identifikovane su promene u pogledu osnaživanja i jačanja njihove asertivnosti i nivoa sreće. Dakle, trening o asertivnosti ne samo da unapređuje komunikacijske veštine, nego i pomaže u regulaciji odnosa i sticanju sposobnosti rešavanja problema (Gultekin, et al, 2018). Zato se može reći da je takav vid edukacije neophodno primeniti u školskom kontekstu, jer bi sticanje veština asertivne komunikacije nastavnika doprinelo konstruktivnom načinu suočavanja za savremenim izazovima i problemima nastavne prakse. Sa druge strane, čas odeljenske zajednice omogućava priliku za primenu radioničarskog rada kao uspešnog oblika putem kojeg se razvija asertivni stil komunikacije učenika.

\section{Primena radioničarskog pristupa u razvijanju asertivne komunikacije učenika na časovima odeljenske zajednice}

Radioničarski rad omogućava kako primenu različitih metoda i tehnika, tako i istraživanje različitih pedagoških problema i pojava. Ovaj način rada daje mogućnosti za adekvatnu realizaciju vaspitnih i obrazovnih ciljeva i unapređivanje kvaliteta nastave.

U proučavanju socijalnih relacija učenika radioničarski pristup ima poseban značaj, jer pruža mogućnost za razumevanje ponašanja učenika i njihovih iskustava u različitim 
životnim kontekstima. Kružna komunikacija, interakcija između učenika i nastavnika i aktivna participacija u aktivnostima omogućava razvijanje socijalnih i emocionalnih kompetencija koje se u odnosu na kognitivne kompetencije u manjoj meri razvijaju u nastavnom procesu. Iz tih razloga radioničarski pristup može biti od vitalnog značaja za razvijanje kvalitetnih odnosa, a nastavnik u ulozi odeljenskog starešine potencijale ovog pristupa može primeniti upravo na času odeljenkse zajednice. Priprema i primer radionice putem koje se može unaprediti asertivna komunikacija učenika i primeniti u okviru časova odeljenske zajednice prikazana je u Tabeli 1 i Tabeli 2.

\section{Tabela 1. Priprema radionice za čas odeljenske zajednice}

\begin{tabular}{|c|c|}
\hline Nastavni predmet & Čas odeljenske zajednice \\
\hline Nastavna jedinica & Komunikacija - aktuelni problemi i mogućnosti unapređivanja \\
\hline Naziv radionice & Asertivnom komunikacijom do uspešnih interpersonalnih odnosa \\
\hline Vrsta radionice & Edukativna radionica \\
\hline Cilj & Osposobljavanje učenika za primenu asertivnog stila komunikacije. \\
\hline Zadaci & $\begin{array}{l}\text { Obrazovni: upoznavanje sa asertivnom komunkacijom, sticanje } \\
\text { znanja o koracima asertivnosti i prednostima koje asertivna } \\
\text { komunikacija pruža. } \\
\text { Vaspitni: razvijanje karakteristika koje čine asertivnu ličnost; } \\
\text { razvijanje odgovornosti za sopstveno ponašanje, osećaja zadovoljstva } \\
\text { i sopstvene vrednosti zbog osposobljenosti za korišćenje veština } \\
\text { asertivne komunikacije; motivisanje učenika za primenu asertivnog } \\
\text { stila komunikacije; i razvoj i podsticanje kulture komunikacije. } \\
\text { Funkcionalni: razvijanje sposobnosti rešavanja problemskih } \\
\text { situacija; i uvežbavanje veština asertivne komunikacije i razvijanje } \\
\text { veštine timskog rada i aktivnog slušanja. }\end{array}$ \\
\hline Oblici rada & Razgovor u krugu, grupna diskusija, rad u malim grupama \\
\hline Tehnike rada & Moždana oluja i igre uloga \\
\hline Očekivani ishodi & $\begin{array}{l}\text { Učenici će unaprediti svoja znanja o asertivnoj komunikaciji i } \\
\text { putem praktičnih vežbi usavršiti svoje veštine komuniciranja i } \\
\text { biće motivisani za dalju primenu asertivnog stila komuniciranja u } \\
\text { svakodnevnom životu. }\end{array}$ \\
\hline Trajanje & 90 minuta \\
\hline Materijal & Papiri za flip čart, papiri A4, stikeri, markeri \\
\hline
\end{tabular}

Iz priloženog (Tabela 1) se može videti da je u pripremnoj fazi potrebno napraviti plan u pogledu utvrđivanja cilja i zadataka radionice koja će se sprovesti, kao i metoda i tehnika, koje će biti primenjene u okviru časa odeljenske zajednice. Važno je osigurati i prostorne i vremenske uslove i pozitivnu pedagošku klimu. S obzirom na to da čas traje 45 minuta, da bi se postigli očekivani ishodi trajanje radionice nužno je produžiti izvan jednog školskog časa, što zahteva motivisanje učenika za aktivan rad i učešće nakon nastave. 
Ključni delatnik u ostvarivanju ciljeva i zadataka radionice je odeljenski starešina. Kako je on administrativni, organizacioni i pedagoški rukovodilac odeljenja, nesumnjivo se njegova uloga posebno ističe kroz vaspitni rad sa učenicima. Od njega se očekuje da dobro poznaje specifičnosti i dinamiku odeljenja, kao i psihofizički, socijalni i emocionalni razvoj svakog učenika (Mihailović i Vrdović, 2015). Odeljenski starešina je osoba koja bi trebalo da pokaže razumevanje za probleme učenika, da omogući bolju socijalizaciju i podstakne učenike da napreduju u skladu sa svojim interesovanjima. Njegov zadatak je da kod učenika razvija kompetencije koje omogućavaju formiranje pozitivnih i demokratskih odnosa, ali i da teži ka ličnom i profesionalnom napredovanju.

S obzirom na to da radioničarski rad pruža mogućnost za saznavanje stavova, mišljenja i ideja učenika, pružanjem slobode govora i formiranjem atmosfere prihvatanja, odeljenskom starešini takav način rada može predstavljati uspešan put ka upoznavanju učenika, pružanju podrške razvoju njegove ličnosti i kompetencija. Međutim, da bi se osigurala pozitivna klima, aktivna participacija, kooperativno učenje i razmena iskustava pri planiranju, dizajniranju i osmišljavanju scenarija radionice treba uzeti u obzir uzrast, nivo znanja i zainteresovanost učenika za učešće u radionici. Važno je kreirati sadržaj tako da svaka aktivnost predstavlja priliku za učenje, a mogući konflikt među učenicima priliku za sticanje veština asertivne komunikacije. Struktura radionice (uvodni, centralni, završni deo i evaluacija) omogućava da nastavnik na času odeljenske zajednice ima jasnu viziju dinamike, procesa i ostvarivanja rezultata. U Tabeli 2 je prikazan tok radionice koja može biti od koristi nastavnicima u razvijanju asertivne komunikacije učenika.

\section{Tabela 2. Tok radionice}

S obzirom na to da radioničarski rad podrazumeva aktivno učešće i dinamičan rad, razredni starešina pre početka uvođenja u temu i predstavljanja cilja radionice definiše pravila rada sa učenicima. Pravila opisuju poželjna ponašanja i donose se u dogovoru sa učenicima. Neka od njih mogu biti: pravilo kruga, slušanja, učestvovanja, diskrecije, dogovorenog vremena, itd. Nakon predstavljanja cilja radionice sa učenicima se izvodi igra „Kod tebe mi se sviđa..." u trajanju od 10 minuta. Cilj ove igre je da se radionica započne u pozitivnoj

Uvodni deo atmosferi, gde se podstiču pozitivni odnosi među učenicima, a ujedno stvaraju povoljni uslovi za interakciju koja sledi u glavnom delu. Igra započinje tako što razredni starešina zajedno sa učenicima formira krug. Nastavnik daje instrukciju: ,Sada pokušajte osobu sa desne strane da predstavite na pozitivan način. Izgovorite njeno ime i nešto što vam se kod nje dopada. Kako bi podstakao učenike da učestvuju nastavnik prvi započinje tako što daje primer: „Ovo je Ivana, kod nje mi se sviđa to što je u komunikaciji sa mnom veoma prijatna." Nakon nastavnika odgovore daju učenici udesno. Igra se završava kada svi učenici budu predstavljeni. 
Nakon uvodne igre nastavnik sa učenicima realizuje aktivnost koja se zove „Odgovori asertivno!“ u trajanju od 60 minuta. Nastavnik aktivnost započinje tehnikom moždana oluja putem koje podstiče učenike da daju što više asocijacija na pojam asertivna komunikacija. Važno je da nastavnik istakne da nema pogrešnih odgovora, a cilj je da davanjem brzih odgovora učenici iznesu što više ideja. Nastavnik odgovore zapisuje na tabli, nakon čega ih čita i komentariše zajedno sa učenicima. Nakon toga sledi kratka prezentacija o asertivnosti, koracima i prednostima asertivne komunikacije putem interaktivnog razgovora za učenicima. U okviru prezentacije važno je da nastavnik korake asertivne komunikacije predstavi kroz primere, kako bi učenici naučili i kasnije praktično uvežbali ovu veštinu. U tu svrhu se može kao primer navesti i tehnika otvaranje koja sadrži JA govor, a podrazumeva:

1. Opažanje - kada se govori o postupku druge osobe ili opisu situacije. Rečenica se može započeti sa „Kada vidim (čujem) da...“.

2. Osećanja - kada se izražavaju sopstvena osećanja, ali bez pravdanja. To je nastavak na prethodnu rečenicu i može glasiti ,...ja osećam...“ ili „,...poželim da...".

3. Potrebe - kada se govori o ishodu koji bi osoba želela da postigne, npr: ,...želela bih da..."ili ,...volela bih da...“.

4. Zahtev - izjašnjavanje sagovornika o predlogu.

Nakon prezentacije nastavnik deli učenike u četiri grupe. Svaka grupa dobija po jednu različitu problemsku situaciju i njihov zadatak je da putem igre uloga odglume i reaguju suprotno od onog što je dato. Učenici slučajnim izborom izvlače papire na kojima su situacije i u okviru svojih grupa se dogovaraju o ulogama i načinima reagovanja u skladu sa koracima asertivne komunikacije. Nakon rada u grupama učenici glume ispred ostalih grupa. Nakon svake odigrane situacije sa učenicima se odvija razgovor u krugu o tome kako su se osećali dok su glumili, da li im je bilo teško da reaguju asertivno u toj situaciji i zašto, da li smatraju da su odgovorili asertivno u skladu sa koracima, da li bi sada drugačije reagovali, da li bi inače reagovali na taj način u svakodnevnim situacijama, itd. Učenicima se ukazuje na važnost razvijanja asertivnosti i prednosti takvog načina komunikacije u odnosu na sebe i druge.

Predlog problemskih situacija za igre uloga:

1. Dve drugarice su se dogovorile da idu zajedno na žurku kod druga koji proslavlja rođendan. Međutim, jedna od njih kasni već 30 minuta. Razgovor započinje ona koja čeka: „Aman, gde si do sad? Znaš koliko te čekam? Ovo je stvarno nedopustivo! Ko zna koliko puta si do sada kasnila i više mi ne pada na pamet da ti tolerišem. Stvarno si bezobrazna! Je l' ti znaš koliko kasnimo na rođendan zbog tebe. Kad nas budu pitali zašto kasnimo ja ću da kažem da je zbog tebe, a ti vidi kako ćeš da se opravdaš!";

2. Odvija se između roditelja (majke ili oca, daje se izbor da odluče) i deteta (dečak ili devojčica). Na roditeljskom sastanku roditelj saznaje da njegovo dete često izostaje sa časova i da ima mnogo neopravdanih izostanaka. S obzirom na to da roditelj nije upoznat sa tim, poziva svoje dete na razgovor. Roditelj kaže:,,Je l' znaš šta mi se danas desilo na roditeljskom sastanku? Kaže meni tvoja razredna: 'Znate Vaše dete ima mnogo neopravdanih, stvarno ne znam kako to da rešimo, ali pretpostavljam da ste vi o svemu obavešteni.' Kad sam čuo/la sram me je pojeo! Da ja doživim da moje dete ima neopravdane, da crvenim ispred svih! Tebi očigledno uopšte nije važna škola, nego nešto drugo. Uopšte ne znam šta da radim sa tobom. Ma, najbolje je da te odmah ispišem iz škole, jer to zaslužuješ!";

Centralni deo

3. Nastavnik pokazuje nezadovoljstvo po pitanju discipline jednog učenika. Obraća se učeniku: „Ja ne znam koliko puta sam ti rekao/la da ću da ti smanjim ocenu iz vladanja zbog takvog ponašanja. Ne znam dokle ćeš više da se ponašaš ovako i da druge maltretiraš na času. Drugi nastavnici se žale, a mene stalno prozivaju zbog tebe. Kako te nije sramota onako divnih roditelja! Još jednom samo da mi se neko požali, ma odmah ću bez razmišljanja da ti smanjim ocenu iz vladanja. Neće niko da te spasi!“;

4. Situacija se odvija između učenika. Jedan od njih pokazuje izuzetne rezultate u matematici i svom drugu (vidno slabijeg uspeha), često završava domaće zadatke. Učenik izražava nezadovoljstvo i kaže: „Ponovo mi tražiš da ti pišem domaći, a znaš da sutra imam takmičenje. Kako možeš da budeš tako bezobziran! Znaš šta sve moram da uradim i ti opet tražiš. Pa uzmi nekad sam da pišeš. Kako ćeš da naučiš kad si tako lenj i nezainteresovan? Samo da znaš ovo je poslednji put da sam ti uradio domaći! “. 
U poslednjem delu učenici učestvuju u aktivnosti „Asertivnost je važna zato što...” koja traje 15 minuta. Igra započinje tako što učenici i nastavnik stoje ukrugu. Nastavnik ih ukratko podseća na temu o kojoj su govorili na radionici i u skladu sa tim im daje instrukcije da svako od učenika započne rečenicu „Asertivnost je važna zato što...“. Dakle, na osnovu onog što su na radionicama naučili učenici imaju zadatak da nastave rečenicu na način koji oni žele. Kada svako od učenika da svoj odgovor nastavnik završava tako što ukratko rezimira, odnosno još jednom ukazuje na važnost asertivne komunikacije i ističe da veruje u učenike da će njihovu asertivnost nastaviti da razvijaju sa svojim vršnjacima i u svakodnevnoj komunikaciji

Završni deo sa drugim ljudima. Potom ih zamoli da svako na praznom papiru napiše svoje ime i prosledi svim učenicima kako bi svako od njih ostavio neku lepu asertivnu poruku kao uspomenu sa radionice.

Nakon završne aktivnosti nastavnik poziva učenike da na izlasku iz učionice na vratima zalepe stikere na kojima će ostaviti svoj komentar o radionici. Cilj evaluacije je dobijanje

Evaluacija povratne informacije od strane učenika o delotvornosti i dopadljivosti radionice, kao i zadovoljstvu načinom rada nastavnika, u cilju procene efikasnosti radionice i njenoj daljoj primeni u vaspitno-obrazovnom radu.

Na osnovu Tabele 2 se može zaključiti da u velikoj meri uspešnost radionice zavisi od veština nastavnika da odgovori na mnogobrojne uloge. Osim što je potrebno da razredni starešina bude dobar planer i organizator, neophodno je i da bude vešt u ulozi moderatora, posmatrača, edukatora, partnera i regulatora socijalnih odnosa. Osetljivost nastavnika na potrebe učenika, dostupnost i pristupačnost, otvorenost prema inicijativama i idejama učenika i motivisanost za rad, u velikoj meri doprinose modelovanju pozitivne i konstruktivne socioemocionalne klime, a čas odeljenske zajednice i primena radioničarskog rada može biti jedan od načina postizanja povezanosti učenika i nastavnika i razvijanja veština asertivne komunikacije.

\section{Zaključak}

Razvijanje veština asertivne komunikacije učenika kroz časove odeljenske zajednice potencijalno doprinosi formiranju njihovih vrednosnih orijentacija, koje se u interakciji sa drugima reflektuju kroz različite oblike društveno-poželjnog ponašanja. Ostvarivanje bogate interaktivnosti podstiče kooperativnost i međusobne odnose učenika i nastavnika, što doprinosi razvijanju interpersonalnih i timskih veština učenika i ostvarivanju kvalitetne pedagoške klime u odeljenju. Demokratizacijom i humanizacijom nastavnog procesa osigurava se efikasno upravljanje odeljenjem, razvija se nenasilna komunikacija, ostvaruje se kompromis i neguje tolerancija i dijalog među učenicima. $U$ tom pogledu važno je ukazati na veću uključenost razrednih starešina u razvoj socijalnih kompetencija učenika, jer kako Jevtić (Jevtić, 2011) navodi jedino socijalno kompetentan nastavnik može razvijati socijalne kompetencije učenika i to u okviru humanistički orijentisanog kurikuluma. Dakle, unapređivanje socijalnih kompetencija nastavnika se vidi kao prioritet u razvijanju socijalno kompetentnog učenika, što ukazuje da školska praksa zahteva modernizaciju obrazovanja nastavnika 
i njegovih profesionalnih uloga. Shodno tome, prepoznaje se i potreba da se nastavnici kao inicijatori i realizatori značajnih promena podrže i motivišu da kontinuirano unapređuju lične i profesionalne kompetencije i da putem refleskivne prakse ostvaruju željene promene kroz realizovanje akcionih istraživanja.

$\mathrm{S}$ obzirom na to da je $\mathrm{u}$ radu predstavljen predlog radionice koja podstiče asertivnu komunikaciju učenika, važno je ukazati na proveru njene efikasnosti u vaspitno-obrazovnoj praksi. Sa druge strane, predlaže se kreiranje preventivnih programa koji bi kod učenika razvijali, ne samo asertivnu komunikaciju, već i ostale komponente socijalnih kompetencija potrebne za život u 21. veku.

\section{Literatura}

Alberti, R., \& Emons, M. (1970). Your perfect right: a guide to assertive behavior. San Luis Obispo, CA: Impact Press. Retrieved from https://bit.ly/2WMq5HC

Ames, D. (2009). Pushing up to a point: assertiveness and effectiveness in leadership and interpersonal dynamics. Research in Organizational Behavior, 29, 111-133. https:// doi.org/10.1016/j.riob.2009.06.010

Eupena, R. (2012). Teacher communication behavior: it's impact to the students' attitude in learning science. International Peer Reviewed Journal, 3, 147-163. http://dx.doi. org/10.7718/ijss.v3i1.35

Felder, R.M., \& Brent, R. (2017). Effective teaching: a workshop. Purdue University. Retrieved from https://bit.ly/2WMWg9I

Galata, S. (2018). Assertiveness and academic achievement motivation of adolescent students in selected secondary schools of Harari Peoples Regional State, Ethiopia. International Journal of Education and Literacy Studies, 6(4), 40-46. http://dx.doi. org/10.7575/aiac.ijels.v.6n.4p.40

Gultekin, A., Ozdemir, A. A., \& Budak, F. (2018). The effect of assertiveness education on communication skills given to nursing students. International Journal of Caring Sciences, 11(1), 395-401. Retrieved from https://bit.ly/3e4ZTxJ

Güven, M. (2010). An analysis of the vocational education undergraduate students' levels of assertiveness and problem-solving skills. Procedia Social and Behavioral Sciences, 2, 2064-2070. Retrieved from https://core.ac.uk/download/pdf/82617567.pdf

Havelka, N. (2000). Učenik i nastavnik u obrazovnom procesu. Beograd: Zavod za udžbenike i nastavna sredstva.

Hojjat, S. K., Golmakani, E., Khalili, M. N., Chenarani, M. S., Hamidi, M., \& Akaberi, A. (2016). The effectiveness of group assertiveness training on happiness in rural adolescent females with substance abusing parents. Global Journal of Health Sciences, 8(2), 156-163. https://doi.org/10.5539/gjhs.v8n2p156

Husić, S. (2009). Moj doprinos odjeljenskoj zajednici. Novi Muallim, 10(38), 122-126. http://dx.doi.org/10.26340/muallim.v10i38.940.g903

Ivanek, P., Musić, H., Mikić, B. i Džibrić, Dž. (2011). Razredna radna klima u funkciji stvaranja kvalitetne komunikacije i interakcije u nastavi. PORTSKI LOGOS, 9(16-17), 59-63. 
Jevtić, B. (2017). The Attitude of Teachers Towards Prosocial Behaviour and Academic Achievement in Serbia. Problems of Education in the 21st Century, 75(1), 34-53.

Jevtić, J. (2011). Socijalna kompetentnost nastavnika. U N. Potkonjak (Ur.), Godišnjak Srpske akademije obrazovanja (str. 645-654). Beograd: Srpska akademija obrazovanja.

Johnson, R. B., \& Onwuegbuzie, A. J. (2004). Mixed methods research: a research paradigm whose time has come. Educational Researcher, 33(7), 14-26. https://doi. org/10.3102\%2F0013189X033007014

Jovanović, M. (2009). O postojećoj komunikaciji u nastavi i neophodnim promenama, Nastava i vaspitanje, 2, 201-215.

Kember, D., Leung, D.Y.P., \& McNaught, C. (2008). A workshop activity to demonstrate that approaches to learning are influenced by the teaching and learning environment. Active Learning in Higher Education, 9(1), 43-56. https://doi. org/10.1177\%2F1469787407086745

Koludrović, M., Jukić, T. i Reić Ergovac, I. (2009). Sagorijevanje na poslu kod učitelja razredne i predmetne nastave te srednjoškolskih nastavnika. Život i škola, 22(2), 235-249.

Lambertz, M. M., \& Blight, M. G. (2016). You don't have to like me, but you have to respect me: the impacts of assertiveness, cooperativeness, and group satisfaction in collaborative assignments. Business and Professional Communication Quarterly, 79(2), 180-199. https://doi.org/10.1177\%2F2329490615604749

Lucander, H., Knutsson, K., Salé, H., \& Jonson, A. (2012).“I'll never forget this": evaluating a pilot workshop in effective communication for dental students. Journal of Dental Education, 76(10), 1311-1316. Retrieved from https://bit.ly/2LEExLo

Mantra, I. B. N. (2017). Promoting primary school teachers' competence through dynamic interactive workshop and partnership. International Journal of Linguistics, Literature and Culture, 3(1), 1-6. Retrieved from https://bit.ly/3cLmJtO

Mihailović, B. i Vdović, Lj. (2015). Odeljenski starešina. Retrieved from https://natasabelic. files.wordpress.com/2017/08/prirucnik-za-rad-odeljenjskog-staresine.pdf

Moon, J. (2009). Achieving success through academic assertiveness: Real life strategies for today's higher education students. New York: Routledge. Retrieved from https:// bit.ly/2z2HiDD

Nestel, D., \& Betson, C. (1999). An evaluation of a communication skills workshop for dentists: cultural and clinical relevance of the patient-centred interview. British Dental Journal, 187, 385-388. https://doi.org/10.1038/sj.bdj.4800286a

Obey-Jordan, K. (2007). The impact of assertive classroom discipline on social skills. Education and Human Development. Master's Theses, 416. Brockport: State University of New York. Retrieved from https://digitalcommons.brockport.edu/ ehd theses/416/

Ørngreen R., \& Levinsen, K. (2017). Workshops as a research methodology. The Electronic Journal of eLearning, 15(1), 70-81. Retrieved from https://eric. ed.gov/?id=EJ1140102

Romek, V. G. (2003). Trening uverennosti v mežličnostnyh otnošeniâh. Sankt-Petersburg: Reč'. Retrieved from http://www.klex.ru/809

Salman, M. F. (2009). Active learning techniques (ALT) in a mathematics workshop: 
Nigerian primary school teachers' assessment. International Electronic Journal of Mathematics Education, 4(1), 23-35. https://doi.org/10.30651/must.v4i1.2267

Sarkova, M., Bacikova-Sleskova, M., Orosova, O., Madarasova Geckova,A., Katreniakova, Z., Klein, D., \& Dijk, J. P. (2013). Associations between assertiveness, psychological well-being, and self-esteem in adolescents. Journal of Applied Social Psychology, 43(1), 147-154. https://doi.org/10.1111/j.1559-1816.2012.00988.x

Uzuntarla, Y., Cihangiroglu, N., Ceyhan, S., \& Ugrak, U. (2016). Analysis of university students' assertiveness level. TAF Preventive Medicine Bulletin, 15(2), 98-104.

Zhamilya I. N., Gulmira B. N., Kundyz K. T., \& Nagibina N. L. (2013). Communication style of teachers and psychological health of students. Middle-East Journal of Scientific Research, 14(10), 1299-1303. https://10.5829/idosi.mejsr.2013.14.10.2329

\title{
ENCOURAGING ASSERTIVE COMMUNICATION OF PUPILS THROUGH WORKSHOP APPROACH WITHIN THE CLASSROOM
}

\author{
Danijela Milosevic \\ University of Nis, Faculty of Philosophy, Department of Pedagogy (PhD student)
}

\begin{abstract}
The study discusses the assertive style of communication as a constructive pattern in the realization of social interactions of pupils and the formation of a quality pedagogical climate in the classroom. The classroom teaching is recognized as an opportunity to develop non-violent communication and democratic relations of pupils, and a teacher is perceived as a key actor in encouraging a cooperative atmosphere and prosocial behavior of pupils. Workshops are presented as an effective form of experiential, cooperative and active learning, which contribute to the regulation of interpersonal relationships of pupils. The practical value of the work is reflected in the presentation of the educational workshop, designed to enable pupils to apply an assertive style of communication. Since the establishment and development of successful interpersonal communication in teaching depends on a teacher, the study points out the importance of developing his/her social competencies. Orientation towards permanent education and continuous development of reflective practice is the priority of the modern teacher, who aspires to change and innovate the teaching process. School practice requires the modernization of teacher education and its professional roles, in order to achieve the educational function and develop pupils' competencies for life in the 21 st century.
\end{abstract}

Keywords: interpersonal relations, nonviolent communication, pedagogical climate, workshop approach, communication styles.

Citiranje članaka: Milošević D. (2020). Podsticanje asertivne komunikacije učenika putem radioničarskog rada u okviru odeljenske zajednice. Godišnjak za pedagogiju, 5(1), 81-92. 